\title{
Mitochondrial fitness and insulin sensitivity in humans
}

\author{
J. Szendroedi • M. Roden
}

Received: 28 January 2008 / Accepted: 15 April 2008 / Published online: 19 September 2008

(C) The Author(s) 2008. This article is published with open access at Springerlink.com

\begin{abstract}
Human mitochondria can be studied either in biopsies or by measuring flux through ATP synthase and phosphocreatine recovery using magnetic resonance spectroscopy. Myocellular ATP production (flux through ATP synthase [fATP]) increases by up to $90 \%$ during $8 \mathrm{~h}$ of insulin stimulation. Fasting mitochondrial function is 14 $40 \%$ lower than in controls in the presence of insulin resistance, as seen in those with type 2 diabetes, their insulin-resistant relatives or the obese. Insulin-stimulated fATP is abolished in insulin-resistant relatives and patients with type 2 diabetes, and patients frequently show decreased mitochondrial size/density. Age, fat mass, physical activity, plasma NEFA and glucose all correlate negatively with mitochondrial function, but it is for methodological reasons difficult to determine whether reduced mitochondrial content or function account for reduced ATP production in insulin resistance. Experimental plasma NEFA elevation appears to inhibit mitochondrial function by interfering with the metabolic actions of insulin, which might explain impaired mitochondrial function in obesity. Alternatively, primary mitochondrial abnormalities, as seen in those with inherited
\end{abstract}

J. Szendroedi $\cdot$ M. Roden

First Medical Department, Hanusch Hospital (Teaching Hospital of the Medical University of Vienna),

Vienna, Austria

J. Szendroedi $\cdot$ M. Roden

Karl-Landsteiner Institute for Endocrinology and Metabolism,

Vienna, Austria

M. Roden $(\square)$

Institute for Clinical Diabetology, German Diabetes Center and

Department of Medicine/Metabolic Diseases,

Heinrich Heine University Düsseldorf,

Auf'm Hennekamp 65,

40225 Düsseldorf, Germany

e-mail: michael.roden@ddz.uni-duesseldorf.de risk of type 2 diabetes, could decrease lipid oxidation, thereby raising circulating and intracellular NEFA levels. In type 2 diabetes, chronic hyperglycaemia and dyslipidaemia could first diminish the function, and subsequently reduce the size or density of mitochondria via oxidative stress and apoptosis. Many questions remain unsolved, including (1) which mechanisms regulate mitochondrial adaptation to nutrient overload; (2) what factors control the expression of genes encoding mitochondrial proteins and other signals involved in mitochondrial biogenesis; (3) which geno/ phenotypes are associated with both insulin resistance and mitochondrial abnormalities; and (4) which are the most promising targets for improving mitochondrial fitness in insulin resistance?

Keywords Ageing · Diabetes mellitus type 2 . Insulin resistance $\cdot$ Magnetic resonance spectroscopy . Mitochondrial function - Mitochondriopathy - NEFA . Oxidative stress $\cdot$ Skeletal muscle $\cdot$ Steatosis

$\begin{array}{ll}\text { Abbreviations } \\ \text { AMPK } & \begin{array}{l}\text { AMP-activated protein kinase } \\ \text { arteriovenous }\end{array} \\ \mathrm{AV} & \text { carnitine palmitoyltransferase-1 } \\ \mathrm{CPT}-1 & \text { flux through ATP synthase } \\ \text { fATP } & \text { long-chain fatty acyl-CoA } \\ \text { LCFA-CoA } & \text { nuclear magnetic resonance spectroscopy } \\ \mathrm{NMR} & \text { mitochondrial DNA } \\ \text { mtDNA } & \text { partial pressure of } \mathrm{O}_{2} \\ p \mathrm{O}_{2} & \text { positron emission tomography } \\ \mathrm{PET} & \text { peroxisome proliferator-activated receptor } \gamma \\ \text { PGC-1 } \alpha & \text { coactivator } 1 \alpha \\ & \text { inorganic phosphate } \\ \mathrm{Pi} & \text { reactive oxygen species } \\ \mathrm{ROS} & \text { tricarboxylic acid } \\ \mathrm{TCA} & \text { uncoupling protein-3 } \\ \mathrm{UCP}-3 & \text { maximum rate of } \mathrm{O}_{2} \text { uptake }\end{array}$




\section{Introduction}

Mitochondria subserve vital processes such as substrate oxidation and energy conversion into ATP, and play an essential role in cellular proliferation, apoptosis and signalling by modulating production of nitric oxide, reactive oxygen species (ROS) and intracellular calcium. Skeletal muscle plays a major role in whole-body energy metabolism, and is responsible for at least $80 \%$ of insulin-stimulated glucose disposal during the euglycaemic-hyperinsulinaemic clamp. In states of insulin resistance, impaired insulinstimulated glucose transport and/or phosphorylation, together with reduced glycogen synthesis, account for more than $50 \%$ of the reduction in whole body glucose disposal $[1,2]$.

Skeletal muscle is primarily responsible for overall insulin resistance and contributes to atherogenic dyslipidaemia and hepatic insulin resistance [3, 4]. Consistent with the view that muscle promotes the conversion of energy from ingested carbohydrate into de novo hepatic lipogenesis and increased lipoprotein production [3, 4], insulin resistance could be caused by impaired mitochondrial fitness or result from increased lipid availability from lipolysis or a high-energy diet. Insulin resistance may also result from increased storage of intracellular triacylglycerol (otherwise known as ectopic fat) in tissues that normally contain negligible amounts, such as intramyocellular lipids and hepatocellular lipids. Increased lipid availability will give rise to intracellular lipid metabolites such as long-chain fatty acyl-CoA (LCFA-CoA) which stimulate inflammatory pathways that interfere with insulin signal transduction, ultimately leading to insulin resistance [5]. The principal metabolic defect in skeletal muscle by which ectopic lipids accumulate might also be a defect in muscular fatty acid oxidation rather than oversupply of substrate [6]. Hyperglycaemia and impaired inhibition of lipolysis resulting from insulin resistance induced glucolipotoxicity which initiates a vicious cycle of metabolic decompensation, especially in association with a sedentary lifestyle and high-fat diet [7]. Reduced mitochondrial function and lipid oxidation would thus give rise to intramyocellular lipid formation and insulin resistance, causing further impairment of mitochondrial function.

This review summarises recent findings in humans concerning muscle energy metabolism, insulin resistance and the mechanisms of adaptive compensation for environmental or inherited factors which predispose to the development of type 2 diabetes.

\section{Methods for studying mitochondria in humans}

Several approaches have been developed to examine human mitochondria, ranging from morphometry and enzymology to functional analysis.
Morphometry

Confocal fluorescence microscopy has shown that mitochondria form a highly organised network within the sarcomeres of human skeletal muscle [8], which most probably undergoes persistent fusions and fissions. Enzyme histochemistry can be used to identify mitochondriopathies through measurement of NADH, ATPase or cytochrome oxidase, and to diagnose deficiencies in mitochondrial proliferation through measurement of succinate dehydrogenase. Electron microscopy allows quantification of mitochondrial density and size and analysis of their distribution between the subsarcolemmal and intermyofibrillar space. Moreover, this technique gives a picture of branching, which is a marker of fusion-fission activity and the morphology of the inner mitochondrial membrane. Furthermore, abnormalities such as paracrystalline inclusions, typical of mitochondriopathies, and vacuoles, often seen in obesity and type 2 diabetes, can be detected and probably represent degenerative processes [9]. An increase in computational power permitted the delineation of the crystal structures of the mitochondrial membrane complexes II-V by means of x-rays [10], furthering our understanding of structural-functional relationships.

\section{Ex vivo functional analyses}

Mitochondrial function can be studied by measuring the activities of enzymes involved in the respiratory chain and substrate oxidation and by more functional methods which monitor ATP production by bioluminescent techniques or $\mathrm{O}_{2}$ consumption with high-resolution respirometry.

Mitochondrial enzyme activities The mitochondrial electron transport chain includes coenzyme Q, cytochrome $c$ and complexes $\mathrm{I}-\mathrm{V}$, which are encoded by both nuclear and mitochondrial DNA (mtDNA), and catalyse energy transduction from substrates to the proton gradient for ATP synthesis. A number of approaches for measurement of the corresponding enzyme activities have been reported [11]. Spectrophotometric assays measure enzyme activities per sample protein mass, reflecting enzyme abundance in the presence of substrate excess using specific inhibitors.

In general, cytochrome $c$, oxidase II and mitochondrial membrane potential serve as a measure of electron transport chain activity, and the activity of $\beta$-hydroxyacyl-CoA dehydrogenase acts as an indicator of $\beta$-oxidation [12]. Citrate synthase activity is a marker of the nuclear expression of genes encoding mitochondrial proteins and a measure of tricarboxylic-acid (TCA) cycle activity. Because expression of the gene encoding citrate synthase can increase following acute exercise or insulin stimulation, stimulation of mitochondrial biogenesis might be more reliably determined by 
measuring mtDNA content relative to nuclear DNA, which is not sensitive to acute metabolic changes [12].

Mitochondrial ATP production and oxygen consumption ATP production can be quantified in suspensions of isolated mitochondria using a bioluminescent technique that involves luciferin-luciferase ATP monitoring [13]. Recent developments in high-resolution respirometry allow the measurement of $\mathrm{O}_{2}$ consumption in preparations of permeabilised muscle fibres and isolated mitochondria [14]. This technique also permits the application of multiple substrate-inhibitor titrations, with the aim of characterising mitochondrial function kinetically.

Protein fractional synthesis rates Muscular mixed and mitochondrial protein fractional synthesis rates allow estimation of the effects of interventions on mitochondrial biogenesis. This method combines infusion of isotopically labelled amino acids with serial muscle biopsies and purification of mitochondria [15]. It can only be applied to subsarcolemmal, but not to intermyofibrillar mitochondria. This results from the use of proteolytic enzymes, which are required for the isolation of intermyofibrillar mitochondria and interfere with any findings [16].

Microarray analysis and gene expression profiling Microarray analysis and gene expression profiling studies in muscle biopsies screen for variables that might trigger skeletal muscle insulin resistance, but only a few studies have compared readouts from molecular genetic techniques with functional properties of mitochondria in human tissue $[17,18]$.

Taken together, despite the advantages of ex vivo techniques, a number of limitations need to be considered. First, the isolation procedure separates mitochondria from their physiological environment. This is partly overcome by studying intact or permeabilised cells. Second, the sensitivity of biochemical analyses is affected by the processing of the biopsy samples, fresh muscle being preferable to frozen specimens. Third, maximal enzyme activities do not necessarily reflect metabolic fluxes and may not be sensitive enough to identify subtle alterations. Because of the limited availability of human tissue biopsy samples, time resolution for detection of dynamic changes is restricted for some ex vivo methods. Of note, only $\sim 10 \mathrm{mg}$ of biopsy sample is needed for high-resolution respirometry. Also, stable preparations permit prolonged steady-state measurements at many different mitochondrial states, not just maximal capacity at saturating substrate concentrations. When comparing measures of mitochondrial function, the observed effects will depend not only on study design, but also on other confounders. Notably, matching study groups for lifestyle factors (stable dietary habits, frequency and intensity of physical activity) and for concentrations of substrates and hormones (e.g. glucose and insulin levels in insulin-resistant or diabetic humans) should be mandatory.

In vivo techniques

Expired gas analysis Expired gas analysis can be performed during resting (indirect calorimetery) and exercise (spiroergometry). Indirect calorimetry provides measures of basal energy expenditure and substrate oxidation, whereas spiroergometry yields rates of maximum $\mathrm{O}_{2}$ uptake $\left(\dot{V} \mathrm{O}_{2 \max }\right)$ during exhausting exercise. Both techniques suffer from limitations [19]. Indirect calorimetry relies on cardiorespiratory conditions and provides sufficient accuracy for estimating total resting energy production (mean coefficients of variation $<5 \%$ ), but not for assessing carbohydrate and fat utilisation (variation $\sim 20 \%$ ) [20]. Spiroergometry additionally depends on the volunteers' musculoskeletal fitness and motivation to reach individual peak exercising capacity [21]. Nevertheless, it is an easy-accessible tool with which to investigate large cohorts [22].

Assessment of arteriovenous differences in $\mathrm{O}_{2}$ partial pressure A more invasive method applies Fick's principle for the local determination of muscular $\mathrm{O}_{2}$ uptake as an indirect estimate of mitochondrial function. This method requires the measurement of blood flow by catheterisation and calculation of regional arteriovenous (AV) differences in $\mathrm{O}_{2}$ partial pressure $\left(\mathrm{O}_{2}\right)$ from haemoglobin $\mathrm{O}_{2}$ saturation [23]. The maximum $\mathrm{AV} p \mathrm{O}_{2}$ difference during exercise may be produced by mitochondrial adaptation or by other muscular (myoglobin content, capillarisation) or systemic (blood flow stimulated by cardiorespiration and $\mathrm{O}_{2}$ delivery to non-muscular tissues) alterations [24]. Nearinfrared spectroscopy involves similar constraints, being a non-invasive method for the determination of the degree of oxygenation of haemoglobin and myoglobin as parameters of blood $\mathrm{O}_{2}$ saturation and tissue haemodynamics. It similarly reflects the dynamic balance between $\mathrm{O}_{2}$ delivery and extraction in the muscle capillary bed without being a direct measure of extraction [25]. One limitation of this method is that the signals cannot be converted into absolute $\mathrm{O}_{2}$ saturation. Thus, relative values within a range defined by the absorption level at rest and at maximal exercise after ischaemia induced by an inflated cuff merely allow for comparison of different groups [25].

Positron emission tomography Use of positron emission tomography to perform kinetic analyses of the dilution of $\left[{ }^{15} \mathrm{O}\right] \mathrm{O}_{2},\left[{ }^{15} \mathrm{O}\right] \mathrm{H}_{2} \mathrm{O}$ and $1\left[{ }^{18} \mathrm{~F}\right]$ fluorodeoxyglucose is a non-invasive method for determining muscular perfusion and assessing $\mathrm{O}_{2}$ and glucose uptake [26]. Tracers have been used to identify metabolic abnormalities associated 
with either the TCA cycle (using $\left[{ }^{11} \mathrm{C}\right]$ acetate) or $\beta$-oxidation (using $\left[{ }^{11} \mathrm{C}\right]$ palmitate) [27]. However, the use of PET scanning is restricted by the high costs of the on-site cyclotrons that are necessary for producing short-lived radio-nuclides and by the exposure of participants to ionising radiation. Moreover, time-course analyses are limited by tracers' halflives, and assumptions have to be made for quantification of glucose transport [28].

Nuclear magnetic resonance spectroscopy Nuclear magnetic resonance spectroscopy (NMR) offers a means of monitoring biochemical fluxes of intracellular metabolites which is non-invasive, direct and quantitative. In this section we discuss ${ }^{31} \mathrm{P}$ NMR and ${ }^{1} \mathrm{H}$ NMR.

Tissues that rapidly consume ATP such as muscle and brain generate phosphocreatine as an energy buffering system for rapid ATP regeneration. Determination of phosphocreatine kinetics using ${ }^{31} \mathrm{P}$ NMR during recovery from a bout of exercise was developed as a tool for estimation of mitochondrial function [29]. During exercise, phosphocreatine concentrations decrease and then rapidly recover, yielding a time constant of the recovery rate that is independent of work or power output [30]. As shown in Fig. 1, this tool shows a high level of sensitivity and could be used to identify patients with mitochondriopathies [31] and to monitor therapeutic interventions [32]. Notably, this technique does not determine maximal rates of ATP synthesis rates, but rather suprabasal dynamic oxidative capacity, since other energy consuming and producing processes (e.g. transmembrane transportation, protein synthesis, glycolysis) are maintained during phosphocreatine resynthesis. Glycolytic ATP synthesis (anaerobic) and oxidative phosphorylation (aerobic) provide the energy for long-lasting muscular work and immediate ATP buffering by the creatine kinase reaction.

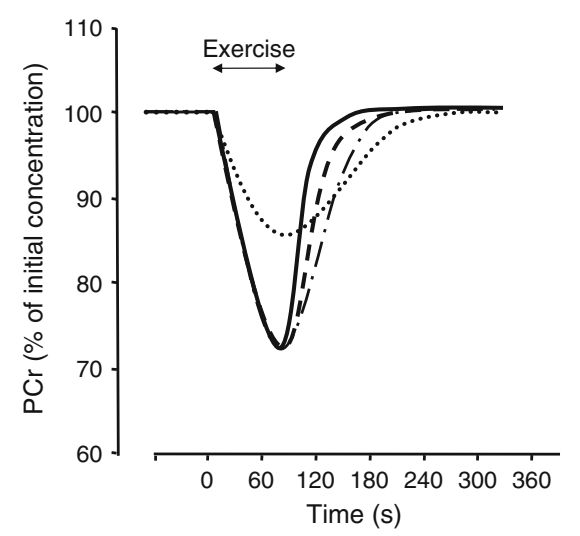

Fig. 1 Time-course of phosphocreatine (PCr) recovery after exercise employing ${ }^{31} \mathrm{P}$ NMR in healthy volunteers (solid line), obese volunteers (dashed line) and patients with type 2 diabetes mellitus (dotted dashed line) and Friedreich's ataxia (dotted line) [31, 72, 102, 103]
Application of the magnetisation saturation transfer experiment to the exchange between inorganic phosphate (Pi) and $\gamma$-ATP provides a direct measurement of the unidirectional flux through ATP synthase (fATP) [33, 34]. Steady-state Pi magnetisation is measured with selective continuous wave irradiation of the $\gamma$-ATP resonance and this is compared with the magnetisation following irradiation placed symmetrically down-field from the Pi frequency. The fractional reduction in Pi magnetisation is due to the exchange of saturated $\gamma$-ATP with non-saturated Pi nuclei (Fig. 2). The respective fractions of Pi magnetisation measured after variable interpulse delay lengths are used to calculate the spin lattice relaxation time for Pi. Employing the Forsen and Hoffman equation yields the unidirectional fATP ( $\mu$ mol $[\mathrm{g} \text { muscle }]^{-1} \mathrm{~min}^{-1}$ ) [34]. Combined ${ }^{13} \mathrm{C} /{ }^{31} \mathrm{P}$ NMR can simultaneously assess oxidation/phosphorylation energy coupling by tracing the flux through the TCA cycle by monitoring ${ }^{13} \mathrm{C}$ incorporation into glutamate during continuous intravenous $\left[{ }^{13} \mathrm{C}\right]$ acetate infusion [35]. We recently developed a fast localisation ${ }^{31} \mathrm{P}$ NMR technique to quantify fATP in human liver, which yielded an fATP of $\sim 30 \mu \mathrm{mol}$ (g liver) $)^{-1} \min ^{-1}$ in healthy young volunteers [36]. It should be noted that the possible contribution of non-mitochondrial ATP turnover in the liver needs to be taken into account when making this calculation.

Increased hepatocellular lipid content correlates negatively with both whole body and hepatic insulin sensitivity, and could be the key factor in the development of insulin resistance and type 2 diabetes [37, 38]. In the absence of alcohol intake or other hepatotoxic agents, hepatocellular lipid accumulation is termed steatosis or non-alcoholic fatty liver [3, 39]. Intracellular lipid deposition in liver and muscle can be quantified by means of ${ }^{1} \mathrm{H}$ NMR. Despite their advantages, these techniques cannot provide an explanation as to whether impaired function is due to alterations in individual mitochondria, a reduction of mitochondrial density (i.e. number and/or size of normally functioning mitochondria), heterogeneity of $\mathrm{O}_{2}$ delivery, or decreased energy demand.

Mitochondrial function under physiological conditions

The fasted state

In young, lean, healthy individuals, mean unidirectional fATP rates measured by ${ }^{31} \mathrm{P}$ NMR range from $\sim 8[40,41]$ up to $12 \mu \mathrm{mol}$ (g muscle) $)^{-1} \min ^{-1}[42,43]$ (Table 1). Muscle ATP production can be markedly reduced in healthy elderly volunteers aged $\sim 70$ years (fATP of $\sim 4 \pm 1 \mu \mathrm{mol} \mathrm{g}{ }^{-1} \mathrm{~min}^{-1}$ ) [40]. On the other hand, middle-aged volunteers (mean age 57 years) have a fATP $\left(\sim 10 \pm 1 \mu \mathrm{mol} \mathrm{g}^{-1} \mathrm{~min}^{-1}\right)$ similar to that observed in lean younger controls (mean age 27 years) $[42,43]$. Interestingly, these middle-aged volunteers also had considerably higher whole body glucose disposal rates 


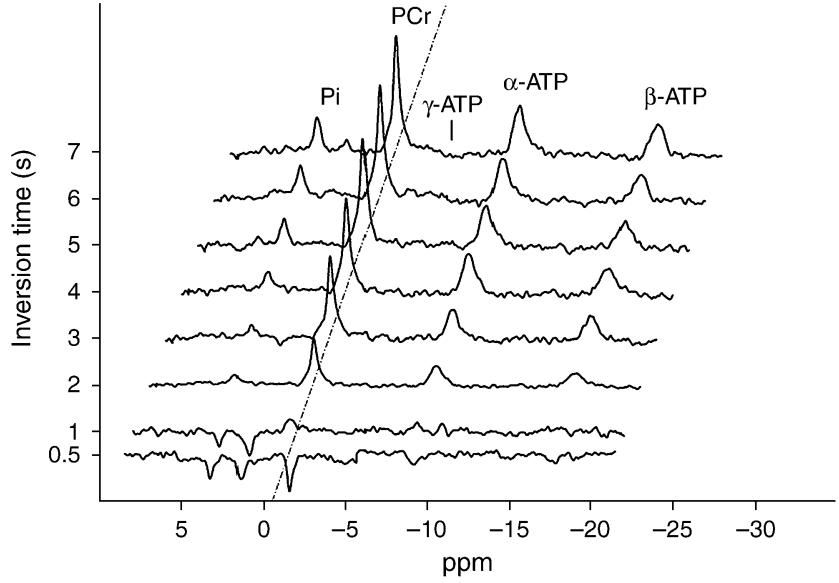

Fig. 2 Assessment of fATP applying the saturation transfer experiment during ${ }^{31} \mathrm{P}$ magnetic resonance spectroscopy in one healthy young volunteer. The ${ }^{31} \mathrm{P}$ spectra were obtained during application of selective continuous wave irradiation of the $\gamma$-ATP in vivo in the gastrocnemius-soleus muscle complex. Sequential spectra show fractional reductions in inorganic phosphate $(\mathrm{Pi})$ magnetisation measured after eight variable interpulse delay lengths ranging from $500 \mathrm{~ms}$ (bottom) to $7 \mathrm{~s}$. PCr, phosphocreatine than the elderly participants of the previous study ( $\sim 0.4$ vs $\sim 0.2 \mathrm{mmol} \mathrm{kg}^{-1} \mathrm{~min}^{-1}$ ) (Table 1). This is in line with the concept that the insulin resistance that emerges during ageing is correlated with, or even results from, reduced mitochondrial function. An age-related decline in mitochondrial function might be due to a reduction in overall and, in particular, insulin-stimulated protein synthesis [43-46], or be related to increasing body mass, insulin resistance and physical inactivity. Adjustment for physical activity might abolish differences in mitochondrial function between young and older persons [47, 48], since exercise stimulates the rate of muscle protein synthesis in both groups [49, 50]. Thus, oxidative capacity can be maintained in humans aged up to 70 years even though mtDNA accumulates mutations and deletions at high rates as a result of impaired DNA repair [51] and exposure to ROS [52].

Insulin-stimulated conditions

Insulin stimulates substrate influx in skeletal muscle [53]. These transmembranous substrate gradients enhance fATP

Table 1 In vivo mitochondrial function in healthy young and elderly individuals and patients with type 2 diabetes and their relatives

\begin{tabular}{|c|c|c|c|c|c|}
\hline \multirow[t]{2}{*}{${ }^{31} \mathrm{P}$ NMR method } & \multirow{2}{*}{$\begin{array}{l}\text { IS glucose disposal } \\
(M \text { value })^{\mathrm{a}}\end{array}$} & \multicolumn{3}{|c|}{ Mitochondrial function } & \multirow[t]{2}{*}{ Ref. } \\
\hline & & Fasting $^{\mathrm{b}}$ & $\begin{array}{l}\text { IS euglycaemia }{ }^{\mathrm{b}} \\
\text { ( } \% \text { change vs fasting) }\end{array}$ & $\begin{array}{l}\text { IS hyperglycaemia }{ }^{\mathrm{b}} \\
\text { (\% change vs fasting) }\end{array}$ & \\
\hline \multicolumn{6}{|c|}{ Healthy young controls } \\
\hline ST & $0.7 \pm 0.2$ & $12 \pm 3$ & $15 \pm 4(+26 \%)$ & & [43] \\
\hline ST & $0.4 \pm 0.2$ & $8 \pm 3$ & & & [40] \\
\hline ST & $0.6 \pm 0.1$ & $9 \pm 2$ & $15 \pm 3(+60 \%)$ & & [42] \\
\hline ST & $0.5 \pm 0.1$ & & $(+90 \%)$ & & {$[53]$} \\
\hline PR & & $26 \pm 11$ & & & [102] \\
\hline PR & & $26 \pm 9$ & & & {$[31]$} \\
\hline PR & & $35 \pm 3$ & & & [102] \\
\hline TCA & $10 \pm 3^{\mathrm{c}}$ & $96 \pm 42$ & & & {$[35]$} \\
\hline \multicolumn{6}{|l|}{ Elderly controls } \\
\hline ST & $0.4 \pm 0.1$ & $10 \pm 3$ & $12 \pm 2(+11 \%)$ & & [43] \\
\hline ST & $0.3 \pm 0.1$ & $4 \pm 3$ & & & [40] \\
\hline PR & $0.3 \pm 0.1$ & & $19 \pm 3^{\mathrm{e}}$ & & {$[72]$} \\
\hline PR & & $32 \pm 3$ & & & [103] \\
\hline \multicolumn{6}{|c|}{ Relatives of type 2 diabetic individuals } \\
\hline ST & $0.3 \pm 0.0$ & & $(+5 \%)$ & & [53] \\
\hline TCA & $3 \pm 1^{\mathrm{c}}$ & $59 \pm 17$ & & & [35] \\
\hline \multicolumn{6}{|c|}{ Type 2 diabetic individuals } \\
\hline $\mathrm{ST}$ & $0.3 \pm 0.1$ & $9 \pm 2$ & $10 \pm 3^{\mathrm{d}}$ & $10 \pm 2^{\mathrm{d}}$ & [43] \\
\hline PR & $0.2 \pm 0.1$ & & $27 \pm 12^{\mathrm{e}}$ & & {$[72]$} \\
\hline PR & & $52 \pm 7$ & & & [103] \\
\hline
\end{tabular}

Data are presented as means \pm SD. Mitochondrial function was assessed by phosphocreatine recovery (PR) or fATP using saturation transfer (ST) during ${ }^{31} \mathrm{P}$ NMR or by TCA cycle activity during ${ }^{13} \mathrm{C}$ NMR

${ }^{\mathrm{a}}$ Units: $\mathrm{mmol}(\mathrm{kg} \text { body weight })^{-1} \mathrm{~min}^{-1}$

${ }^{\mathrm{b}}$ Units: for ST, $\mu \mathrm{mol}$ (g muscle) ${ }^{-1} \mathrm{~min}^{-1}$; for PR, s; for TCA, nmol (g muscle) ${ }^{-1} \mathrm{~min}^{-1}$

${ }^{\mathrm{c}}$ Insulin sensitivity index (isi)

${ }^{\mathrm{d}}$ non significant vs fasting

${ }^{\mathrm{e}}$ Measured at $2 \mathrm{~h}$ postprandially

IS, insulin-stimulated 
until a new equilibrium is reached $[54,55]$, and this immediate insulin effect on fATP might last for up to $\sim 4 \mathrm{~h}$ $[42,43,56]$. During prolonged hyperinsulinaemia, increased electron chain enzyme activities via allosteric stimulation (starting at 1-3 h) and mitochondrial protein production (after $\sim 6 \mathrm{~h}$ ) further augment fATP [56]. Insulin stimulation has been reported to increase fATP in muscle mitochondria by $10-16 \%$ in vivo after $4 \mathrm{~h}$ and by $32-42 \%$ in vitro after $8 \mathrm{~h}[42,43,53]$. Use of ${ }^{31} \mathrm{P}$ NMR in combination with the euglycaemic-hyperinsulinaemic clamp technique revealed that fATP increases by $\sim 26$ $90 \%$ at $30-240 \mathrm{~min}$ in young, lean, healthy humans and by $\sim 11 \%$ at $120-240 \mathrm{~min}$ in insulin-sensitive elderly humans (Table 1).

Mitochondrial function under pathophysiological conditions

\section{Mitochondriopathies}

Most mitochondriopathies are associated with maternally inherited mutations of mtDNA and of nuclear DNA encoding mitochondrial proteins. Diabetes is commonly present in mitochondriopathies resulting from impaired glucose-stimulated insulin secretion caused by insufficient supply of ATP and GTP [57-59]. Insulin sensitivity can be, but is not generally, decreased in mitochondrial diabetes [31]. We have identified one patient with MELAS (myopathy, encephalopathy, lactate acidosis, stroke-like episodes) syndrome with not only reduced fasting and insulin-stimulated fATP but also insulin resistance, despite no accumulation of intramyocellular lipid [60]. This suggests that mitochondrial dysfunction at least contributes to insulin resistance. Friedreich's ataxia, another mitochondrial disease associated with an increased risk of diabetes, leads to increased ROS production [31] and reduced mitochondrial function (Fig. 1) [61]. Interestingly, in patients with treated acromegaly fATP is reduced by $\sim 25 \%$ and beta cell function is impaired, indicating that acquired endocrine alterations can also induce prolonged mitochondrial dysfunction [62].

\section{Insulin-resistant conditions}

Cellular metabolites such as LCFA-CoA, originating from NEFA; diacylglycerol, originating from membrane-bound phosphatidylinositol; and ceramide, generated by sphingomyelin hydrolysis, inhibit insulin signalling by serine/ threonine phosphorylation of insulin receptor substrates [5]. Many studies have provided evidence of abnormalities in mitochondrial number/size, structure and function in insulin-resistant states. It is as yet unclear as to whether these alterations are primary or secondary, i.e. produced by ageing and/or changes in endocrine and metabolic conditions associated with insulin resistance.

The fasted state In patients with type 2 diabetes and uncontrolled glycaemia (mean $\mathrm{HbA}_{1 \mathrm{c}} 7.5-8 \%$ ), citrate synthase activity is $\sim 14-20 \%$ lower than that observed in lean healthy controls. This is consistent with a reduced cellular mitochondrial content, but does not rule out functional impairment $[9,63]$. Of note, there was no difference in mitochondrial function between type 2 diabetic and obese patients [64]. Cellular mitochondrial content was reduced in both groups, while electron transport chain activity was diminished in subsarcolemmal mitochondria of the type 2 diabetic group only [64]. Complex I and citrate synthase activities were $\sim 40 \%$ and $\sim 19 \%$ lower, respectively, in type 2 diabetic patients than in obese and lean healthy humans [9]. In this study, mitochondrial size and complex I activity showed a negative relationship with insulin resistance [9]. However, these correlations were not adjusted for fat mass, which is negatively associated with complex I activity. These studies reported morphological abnormalities in mitochondria across the whole cell, whereas enzyme activities were predominantly assessed in the subsarcolemmal compartment. Of note, Ritov et al. [64] found that complex II activity was reduced only in the subsarcolemmal mitochondria of patients with type 2 diabetes. On the other hand, Boushel et al. recently demonstrated reduced complex I and II activities in type 2 diabetes when expressed per unit mass of skeletal muscle [65]. They concluded that mitochondrial function in type 2 diabetes is comparable to that in healthy, overweight, age- and BMI-matched individuals and that blunting of respiration in type 2 diabetes could be attributed to lower mitochondrial content. Although mtDNA content per tissue mass was $\sim 19 \%$ lower, the ratio of mtDNA:total DNA was not altered in type 2 diabetes, providing no evidence for reduced mitochondrial content. In this study, type 2 diabetic patients were not compared with young, lean individuals, thus largely excluding effects secondary to aging and obesity. Since no measure of insulin sensitivity was reported, effects of differences in insulin sensitivity cannot be evaluated.

Glycolytic fast-twitch type IIb fibres generally show less oxidative enzyme activity and higher glycolytic enzyme activity than oxidative slow-twitch type I or oxidative fasttwitch type IIa fibres [66]. Some groups have therefore tried to establish whether differences in proportions of fibre types could explain variation in mitochondrial function in type 2 diabetes, and increased proportions of type IIb fibres have been reported by several [67-69], though not all, studies [70].

The observation that establishment of near-normoglycaemia in patients with poorly controlled type 2 diabetes normalised the transcription of genes involved in oxidative phosphory- 
lation indicates that metabolic and endocrine control affect mitochondrial function [71]. Thus, mitochondrial function in type 2 diabetes was found to be 'normal' when glucoselowering medication was withdrawn 1 day before the experiment [65], but was impaired 2 weeks after withdrawal of medication [63]. Other endocrine influences on mitochondrial function have recently been reviewed [58]. To rule out effects of glucotoxicity, we compared the fATP of a group of non-obese type 2 diabetic patients with good metabolic control (mean $\mathrm{HbA}_{1 \mathrm{c}} 6.9 \%$ ) with that of a lean young control group and an older group matched for age, physical activity and BMI [43] (Table 1). The fATP was $\sim 27 \%$ lower in type 2 diabetic patients than in young individuals and tended to be lower than in older controls. Interestingly, these older controls had a higher fATP than those in a previous study [40] that reported $\sim 50 \%$ lower fATP compared with young controls. Only fasting plasma NEFA and WHR, a marker of visceral adiposity, independently predicted fasting fATP across the entire study population (Fig. 3).

Using phosphocreatine recovery, Schrauwen-Hinderling et al. [72] reported impaired mitochondrial function in type 2 diabetes (mean $\mathrm{HbA}_{1 \mathrm{c}}$ 7.3\%) in the face of unchanged intramyocellular lipid levels (Fig. 1, Table 1). Likewise, we found no difference in intramyocellular lipid levels, but hepatocellular lipid levels were four- to sevenfold higher in type 2 diabetes than in the young and elderly control groups [43]. Accordingly, excessive hepatic lipid storage relates to insulin resistance, hepatocellular mitochondrial dysmorphology, depletion of mtDNA and decreased ECT activity $[3,73,74]$

In summary, mitochondrial function was either unchanged or reduced and inconsistently related to measures of insulin sensitivity in different groups of patients with overt type 2 diabetes. In addition to differences in body fat mass and age, variations in circulating insulin and substrate levels limit the conclusions that can be drawn from these data. Thus, it remains unclear at present whether impaired mitochondrial fitness is the cause or the consequence of insulin resistance.

To evaluate the role of mitochondrial function in inherited insulin resistance, normoglycaemic but insulin-resistant first-degree relatives of patients with type 2 diabetes have been examined. These exhibit decreased muscular glucose transport/phosphorylation and glycogen synthesis and reduced $\dot{V} \mathrm{O}_{2 \max }$. These changes are independent of habitual physical activity, increased circulating NEFA levels, ectopic lipid deposition and defective insulin secretion [22, 41, 75, 76]. In non-diabetic relatives of type 2 diabetic patients, a recent DNA microarray study found that muscular peroxisome proliferator-activated receptor $\gamma$ coactivator $1 \alpha$ (PGC-1 $\alpha$ ), which activates genes controlling oxidative metabolism, was reduced [17]. Consistent with this, another study showed that mtDNA content was reduced in nondiabetic relatives of type 2 diabetic patients compared with that in individuals with no family history of diabetes, and was related to insulin resistance and impaired switching of substrate oxidation in response to a high-fat diet [77]. Compared with young healthy controls, insulin-resistant relatives of individuals with type 2 diabetes showed decreased cytochrome $c$ oxidase activity (by $\sim 50 \%$ ) and mitochondrial density (by $\sim 38 \%$ ), increased intramyocellular lipid levels (by $\sim 60 \%$ ), decreased glucose uptake (by $\sim 60 \%$ ), increased IRS-1-serine phosphorylation (by $\sim 50 \%$ ) and reduced insulin-stimulated Akt activation (by 60\%). However, mtDNA copy number and levels of key regulators of biogenesis, e.g. PGC- $1 \alpha$ and $-1 \beta$ and nuclear respiratory factors 1 and 2, were unaffected [78]. This is consistent with impairment of mitochondrial function in relation to insulin resistance, which predisposes insulin-resistant relatives to intramyocellular lipid accumulation. This, in turn, activates a serine kinase cascade, leading to defective
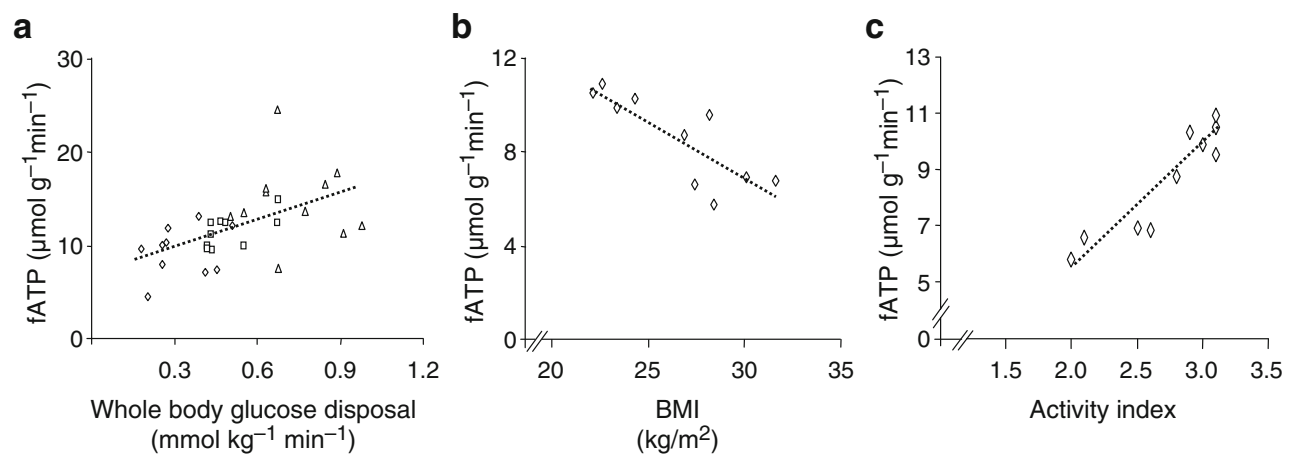

Fig. 3 a Correlation $(R=0.531, p=0.002)$ of fATP during insulin stimulation with insulin sensitivity (whole body glucose disposal) in healthy young (triangles), elderly (squares) and type 2 diabetic humans (diamonds). Correlation of and fATP at baseline with BMI (b Spearman correlation coefficient, $R=-0.826, p=0.003$ ) and the physical activity index (c $R=0.932, p<0.001)$ in type 2 diabetic humans [43] 
insulin signalling and action in muscle. The reason for the inconsistency between these studies might relate to the fact that the insulin-resistant relatives described in the latter study were young, lean and healthy [78], whereas the participants in the other studies were older, obese and diabetic. Petersen et al. used ${ }^{31} \mathrm{P}$ NMR and found that insulin-resistant relatives of individuals with type 2 diabetes have a $\sim 30 \%$ lower fasting fATP, $\sim 80 \%$ higher intramyocellular lipid, but similar hepatocellular lipid levels compared with insulin-sensitive controls [41] (Table 1). These relatives also have reduced insulin-stimulated fATP and Pi transport into skeletal muscle, which hints at coupling of these processes [53]. However, in contrast to potentially inherited defects in mitochondrial biogenesis, it is possible that these alterations result from acquired defects such as lipid-mediated interference with insulin signalling. In line with this, a recent analysis demonstrated that systemic oxidative stress is related to insulin resistance in relatives of individuals with type 2 diabetes even after adjustment for BMI [79], but extended longitudinal studies of individuals at risk would be needed to prove causal relationships.

The insulin-stimulated state Ex vivo muscle biopsy studies demonstrated that citrate synthase activity and ATP production do not increase in obese individuals with untreated type 2 diabetes during prolonged hyperinsulinaemicnormoglycaemic clamps for $6-8 \mathrm{~h}$ [56]. To examine in vivo mitochondrial function, we monitored fATP, glucose transport/phosphorylation and intramyocellular lipid with ${ }^{1} \mathrm{H} /{ }^{31} \mathrm{P}$ NMR during hyperinsulinaemic-normoglycaemic clamps for $4 \mathrm{~h}$ in individuals with type 2 diabetes and older and younger control groups [43] (Table 1). The type 2 diabetic participants were non-obese, had metabolically well-controlled diabetes and were matched to the controls in terms of physical activity. The fATP was not affected by insulin stimulation in the type 2 diabetic group, but was markedly increased in both control groups. Insulin sensitivity explained $\sim 30 \%$ of the variation in insulin-stimulated fATP. Other contributing factors included hepatocellular lipid and fasting plasma NEFA.

In a recent study, biopsy samples from muscles of obese individuals with hyperglycaemic type 2 diabetes were obtained before and $30 \mathrm{~min}$ after oral ingestion of $75 \mathrm{~g}$ of glucose [65]. The rise in plasma glucose and insulin did not change $\mathrm{O}_{2}$ flux rates, suggesting a defect in insulinstimulated mitochondrial function. Likewise, myotubes from lean and obese, but not from type 2 diabetic, participants responded to incubation with insulin for $4 \mathrm{~h}$ with a $\sim 30-\%$ increase in citrate synthase activity. Simultaneous addition of palmitate diminished the stimulatory effect of insulin in myotubes from controls, suggesting that NEFA-induced insulin resistance might interfere with insulin-stimulated mitochondrial function [80]. To examine the effect of increased levels of NEFA on mitochondrial function and its relationship with lipid-induced insulin resistance in vivo, we measured intramyocellular glucose transport/phosphorylation by measuring glucose 6-phosphate, fATP and intramyocellular lipid by ${ }^{31} \mathrm{P} /{ }^{1} \mathrm{H}$ NMR during euglycaemic-hyperinsulinaemic clamp tests [42]. Short-term elevation of plasma NEFA levels reduced the insulinstimulated increase in fATP similar to the impairment of fATP reported for insulin-resistant humans [53, 56]. The changes in intramyocellular glucose 6-phosphate were strongly correlated with fATP, confirming the tight connection between insulin-stimulated glucose disposal and fATP. However, lipid-induced insulin resistance and impaired mitochondrial function were not related to intramyocellular lipid content, suggesting that lipid deposition is not pathogenically relevant [42].

\section{Adaptive capacity of mitochondrial function and mechanisms of regulation}

In addition to decreased oxidative phosphorylation gene expression, altered mitochondrial size, number, function, localisation $[9,64,78,81]$ and generally reduced oxidative capacity $[41,43]$, defective adaptation mechanisms seem to play a pivotal role in mitochondrial dysfunction (Fig. 4).

\section{Metabolic flexibility}

Based on the concept that the ratio of the fluxes through the glycolytic and oxidative pathways is involved in the plasticity of muscle metabolism [82], several groups have consistently demonstrated a relative increase of glycolytic (e.g. phosphofructokinase, glyceraldehyde-3-phosphate dehydrogenase, hexokinase) over oxidative (e.g. citrate synthase, cytochrome $c$ oxidase) enzyme activities in obese, physically inactive individuals, and persons with a family history of or with overt type 2 diabetes [63, 77, 83, 84]. Reduced activation of pyruvate dehydrogenase or impaired inhibition of carnitine palmitoyltransferase-1 (CPT1) complexes by insulin are examples of molecular disturbances that could be responsible for metabolic inflexibility [85, 86]. Similarly, the in vivo thermic effect of insulin and glucose, as measured by indirect calorimetry, has been reported to be blunted in insulin-resistant states, possibly reflecting genetically reduced energy expenditure or 'insulin resistance of the mitochondria' [87, 88]. It was later discovered that insulin stimulates in vitro mitochondrial function by increasing mitochondrial protein levels, thereby augmenting mitochondrial ATP production in lean healthy, but not in diabetic, humans [56]. 


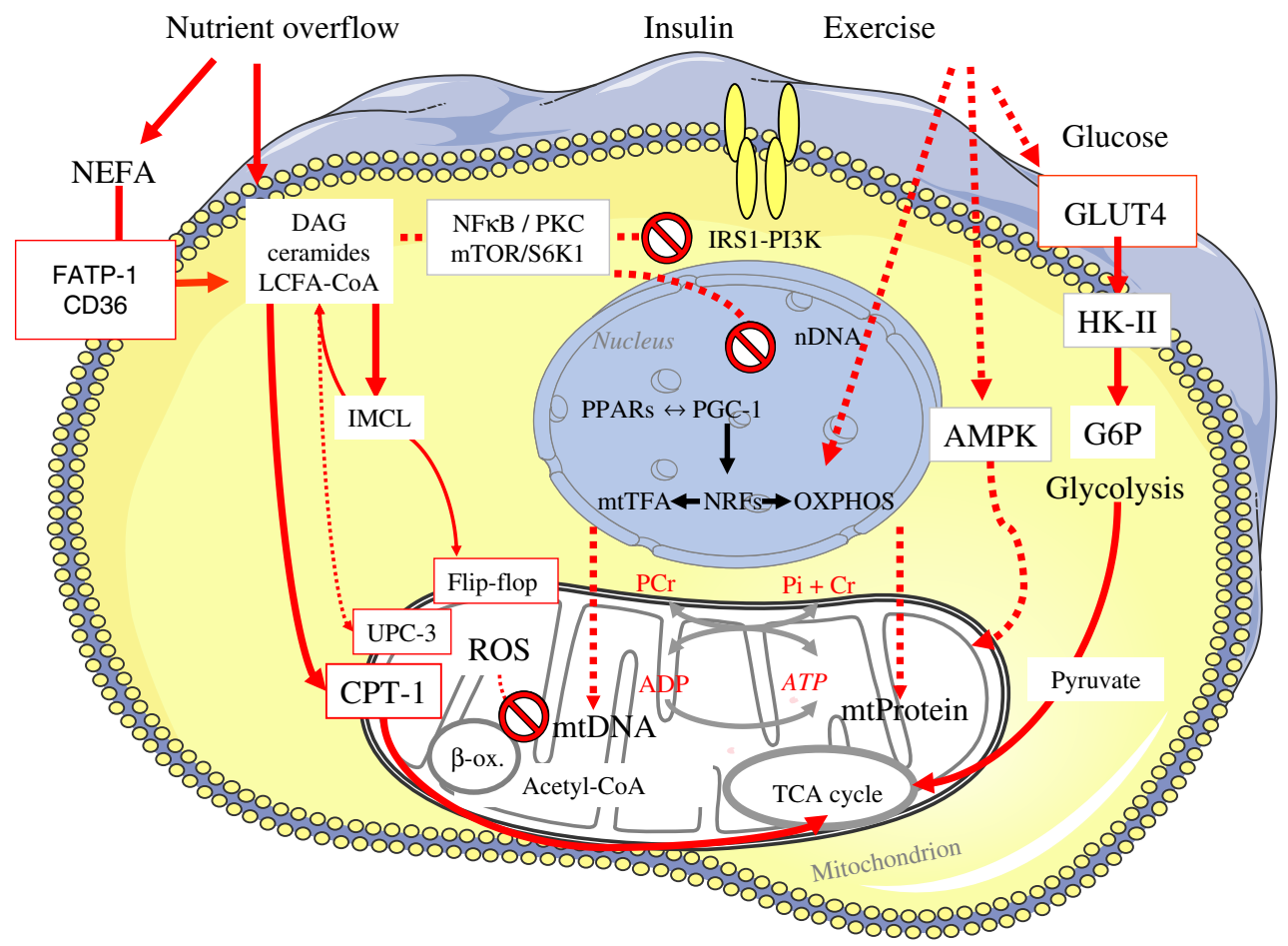

Fig. 4 Schematic diagram summarising the interaction between lipids, insulin action and mitochondrial function in skeletal muscle. The transporters are indicated by red borders; metabolites, no border; enzymes, grey border; phosphorus metabolites, red type. AMPK, AMP-activated protein kinase; DAG, diacylglycerol; FATP-1, fatty acid transport protein 1; G6P, glucose 6-phosphate; HK-II, hexokinase II;

\section{Transport of NEFA}

Production of membrane-bound fatty acid binding protein is upregulated in the endurance-trained state, and is probably instrumental in enhancing lipid oxidation rates [89]. Inhibiting the uptake and cellular distribution of NEFA to the sites where it is metabolised protects against insulin resistance during lipid loading in mice lacking adipocytespecific fatty acid binding protein [90]. However, following intracellular uptake, NEFA can activate AMP-activated protein kinase (AMPK), which inactivates acetyl-CoA carboxylase and consequently decreases malonyl-CoA levels, thereby increasing lipid oxidation (Fig. 4). Hence, NEFA per se effectively facilitate intracellular lipid allocation [91, 92].

Uncoupling protein-3 (UCP-3) is expressed in human skeletal muscle and can be induced by fasting-induced NEFA-release and a high-fat diet. In states of excess mitochondrial NEFA supply, LCFA-CoA accumulates and the CoA pool in the mitochondrial matrix declines, inhibiting oxidation of partially metabolised NEFA. UCP-3 might provide an overflow pathway for NEFA in concert with mitochondrial thioesterase-1 (Fig. 4). Liberation of CoA by mitochondrial thioesterase and export of NEFA anions by UCP-3 would allow for greater rates of lipid
MT1, mitochondrial thioesterase-1; mtTFA, mitochondrial transcription factor A; mTOR, mammalian target of rapamycin; mtProtein, mitochondrial protein; nDNA, nuclear DNA; NFkB, nuclear factor $\mathrm{kB}$; OXPHOS, oxidative phosphorylation; $\beta$-ox., $\beta$-oxidation; $N R F s$, nuclear respiratory factors; PCr, phosphocreatine; PKC, protein kinase C; PPARs, peroxisome proliferator-activated receptors; S6K1, S6 kinase 1

oxidation and reduce the membrane potential, alleviating ROS production [93, 94].

CPT1 catalyses the rate-limiting step of NEFA transport into the mitochondrion. Malonyl-CoA, a potent inhibitor of CPT1, is considered a key regulator of lipid oxidation [95]. Schrauwen et al. proposed alternatively that during excess NEFA supply, a larger fraction enters the matrix via a transmembrane flip-flop mechanism as opposed to the CPT1 system [96, 97] (Fig. 4). Due to a lack of acyl-CoA synthase, NEFA would not be metabolised to LCFA-CoA, increasing the risk of mitochondrial lipid peroxidation. UCP-3-mediated NEFA export would protect against such damage and mitigate ROS production, which corresponds to the former 'NEFA cycling model' [98]. Echtay et al. proposed a mechanism involving the activation of a UCP-3mediated proton leak by 4-hydroxynonenal, a by-product of lipid peroxidation [99]. Thus, a negative feedback loop to reduce the transmembrane proton-motive force would again reduce ROS production. Hence, prolonged NEFA exposure may result in continuous uncoupling, leading to mitochondrial fatigue and sustained reduction of oxidative capacity. Impaired defence mechanisms against ROS, such as superoxide dismutases, catalase and a variety of peroxidases, will lead to accumulation of defective mtDNA. 
Hypothesis of incomplete lipid oxidation

Recently, another mechanism was proposed in which augmented lipid uptake into mitochondria, occurring under conditions of low PGC- $1 \alpha$ content, leads to a mismatch of increased $\beta$-oxidation and decreased TCA and electron transport chain activities, triggering the accumulation of $\beta$-oxidative intermediates. Glucose-tolerant relatives of type 2 diabetic individuals, glucose-intolerant humans and patients with overt type 2 diabetes exhibit reduced muscular levels of PGC- $1 \alpha$ and oxidative phosphorylation genes, which could determine background susceptibility for insulin resistance. Studies employing overexpression of the gene encoding PGC- $1 \alpha$ suggested a shift from 'incomplete' to complete $\beta$-oxidation and reversal of insulin resistance via adaption to lipid overload [100]. Accordingly, insulin sensitivity is closely related to fasting whole body lipid oxidation, but not to intramyocellular lipid levels, in relatives of individuals with type 2 diabetes [101], which further supports the notion that impaired lipid oxidation is related to insulin resistance. In conclusion, under conditions of lipid overload, impaired lipid partitioning between cytosol and mitochondria can result in progressive accumulation of lipid metabolites and mitochondrial dysfunction.

\section{Conclusions and outlook}

Fasting mitochondrial function is not generally impaired in insulin-resistant states, whereas insulin-stimulated fATP is uniformly abolished in insulin-resistant relatives of and patients with type 2 diabetes. Of note, age, fat mass, plasma NEFA and glucose correlate negatively with mitochondrial function. Moreover, methodological differences between studies make it difficult to conclude whether reduced mitochondrial fitness or insulin resistance per se account for reduced ATP production associated with insulinresistant states. In this context, many studies exploring mitochondrial function did not assess physical activity or insulin sensitivity. It is also unclear to what extent reduced oxidative capacity relates to the subfraction of subsarcolemmal mitochondria, whereas less information is available on intermyofibrillar mitochondria because of the use of differential centrifugation in the absence of proteases.

At present, there is evidence that well-characterised insulin-resistant relatives of type 2 diabetic patients suffer from abnormalities in mitochondrial number and function, whereas patients with overt type 2 diabetes exhibit insulin resistance in response to acute changes in mitochondrial function [43]. As the majority of type 2 diabetic patients mostly also show increased plasma NEFA and glucose levels, these findings support the view that these patients develop adaptive mechanisms that improve their basal ATP turnover.
Nevertheless, many questions, including the following remain unsolved: (1) Which mechanisms regulate mitochondrial adaptation to nutrient overload? (2) Which factors control gene expression of mitochondrial proteins and signals involved in mitochondrial biogenesis? (3) Which geno/phenotypes are associated with both insulin resistance and mitochondrial abnormalities? (4) Which targets are promising for improving mitochondrial fitness in insulin resistance?

Acknowledgements Studies conducted at the authors' laboratory were supported by continuous funding from the Austrian Science Foundation (FWF), Austrian National Bank (ÖNB), European Foundation for the Study of Diabetes (EFSD, supported by Novo Nordisk and GlaxoSmithKline) and by grants from the Juvenile Diabetes Research Foundation (JDRF), Herzfelder Family Trust and Hochschuljubiläumsstiftung Vienna to M. Roden.

Duality of interest The authors declare that there is no duality of interest associated with this manuscript.

Open Access This article is distributed under the terms of the Creative Commons Attribution Noncommercial License which permits any noncommercial use, distribution, and reproduction in any medium, provided the original author(s) and source are credited.

\section{References}

1. Roden M, Shulman GI (1999) Applications of NMR spectroscopy to study muscle glycogen metabolism in man. Annu Rev Med 50:277-290

2. Shulman GI, Rothman DL, Jue T, Stein P, DeFronzo RA, Shulman RG (1990) Quantitation of muscle glycogen synthesis in normal subjects and subjects with non-insulin-dependent diabetes by ${ }^{13} \mathrm{C}$ nuclear magnetic resonance spectroscopy. $\mathrm{N}$ Engl J Med 322:223-228

3. Roden M (2006) Mechanisms of disease: hepatic steatosis in type 2 diabetes - pathogenesis and clinical relevance. Nat Clin Pract Endocrinol Metab 2:335-348

4. Petersen KF, Dufour S, Savage DB et al (2007) The role of skeletal muscle insulin resistance in the pathogenesis of the metabolic syndrome. Proc Natl Acad Sci USA 104:12587-12594

5. Petersen KF, Shulman GI (2006) Etiology of insulin resistance. Am J Med 119:S10-S16

6. Kelley DE, Goodpaster B, Wing RR, Simoneau JA (1999) Skeletal muscle fatty acid metabolism in association with insulin resistance, obesity, and weight loss. Am J Physiol 277:E1130-E1141

7. Roden M (2005) Muscle triglycerides and mitochondrial function: possible mechanisms for the development of type 2 diabetes. Int $\mathrm{J}$ Obes (Lond) 29(Suppl 2):S111-S115

8. Shaw CS, Jones DA, Wagenmakers AJ (2008) Network distribution of mitochondria and lipid droplets in human muscle fibres. Histochem Cell Biol 129:65-72

9. Kelley DE, He J, Menshikova EV, Ritov VB (2002) Dysfunction of mitochondria in human skeletal muscle in type 2 diabetes. Diabetes 51:2944-2950

10. Tsukihara T, Aoyama H, Yamashita E et al (1995) Structures of metal sites of oxidized bovine heart cytochrome $c$ oxidase at $2.8 \AA$ A. Science 269:1069-1074 
11. Reisch AS, Elpeleg O (2007) Biochemical assays for mitochondrial activity: assays of TCA cycle enzymes and PDHc. Methods Cell Biol 80:199-222

12. Rabol R, Boushel R, Dela F (2006) Mitochondrial oxidative function and type 2 diabetes. Appl Physiol Nutr Metab 31:675-683

13. Wibom R, Hagenfeldt L, von Dobeln U (2002) Measurement of ATP production and respiratory chain enzyme activities in mitochondria isolated from small muscle biopsy samples. Anal Biochem 311:139-151

14. Gnaiger E, Mendez G, Hand SC (2000) High phosphorylation efficiency and depression of uncoupled respiration in mitochondria under hypoxia. Proc Natl Acad Sci USA 97:11080-11085

15. Short KR, Vittone JL, Bigelow ML, Proctor DN, Nair KS (2004) Age and aerobic exercise training effects on whole body and muscle protein metabolism. Am J Physiol Endocrinol Metab 286:E92-E101

16. Balagopal P, Ford GC, Ebenstein DB, Nadeau DA, Nair KS (1996) Mass spectrometric methods for determination of $\left[{ }^{13} \mathrm{C}\right]$ Leucine enrichment in human muscle protein. Anal Biochem 239:77-85

17. Patti ME, Butte AJ, Crunkhorn S et al (2003) Coordinated reduction of genes of oxidative metabolism in humans with insulin resistance and diabetes: Potential role of PGC1 and NRF1. Proc Natl Acad Sci USA 100:8466-8471

18. Mootha VK, Lindgren CM, Eriksson KF et al (2003) PGC1alpha-responsive genes involved in oxidative phosphorylation are coordinately downregulated in human diabetes. Nat Genet $34: 267-273$

19. Weekes CE (2007) Controversies in the determination of energy requirements. Proc Nutr Soc 66:367-377

20. Gasic S, Schneider B, Waldhausl W (1997) Indirect calorimetry: variability of consecutive baseline determinations of carbohydrate and fat utilization from gas exchange measurements. Horm Metab Res 29:12-15

21. Van de Veire NR, Van Laethem C, Philippe J et al (2006) VE/ $\mathrm{VCO} 2$ slope and oxygen uptake efficiency slope in patients with coronary artery disease and intermediate peakVO2. Eur $\mathrm{J}$ Cardiovasc Prev Rehabil 13:916-923

22. Thamer C, Stumvoll M, Niess A et al (2003) Reduced skeletal muscle oxygen uptake and reduced beta-cell function: two early abnormalities in normal glucose-tolerant offspring of patients with type 2 diabetes. Diabetes Care 26:2126-2132

23. Midgley AW, McNaughton LR, Polman R, Marchant D (2007) Criteria for determination of maximal oxygen uptake: a brief critique and recommendations for future research. Sports Med 37:1019-1028

24. Bassett DR Jr, Howley ET (2000) Limiting factors for maximum oxygen uptake and determinants of endurance performance. Med Sci Sports Exerc 32:70-84

25. Wilson JR, Mancini DM, McCully K, Ferraro N, Lanoce V, Chance B (1989) Noninvasive detection of skeletal muscle underperfusion with near-infrared spectroscopy in patients with heart failure. Circulation 80:1668-1674

26. Nuutila P, Peltoniemi P, Oikonen V et al (2000) Enhanced stimulation of glucose uptake by insulin increases exercisestimulated glucose uptake in skeletal muscle in humans: studies using $\left[{ }^{15} \mathrm{O}\right] \mathrm{O}_{2},\left[{ }^{15} \mathrm{O}\right] \mathrm{H}_{2} \mathrm{O},\left[{ }^{18} \mathrm{~F}\right]$ fluoro-deoxy-glucose, and positron emission tomography. Diabetes 49:1084-1091

27. Miyabe H, Ohte N, Iida A, Narita H, Yoshida T, Kimura G (2005) Evaluation of fatty acid beta-oxidation in patients with prior myocardial infarction in relation to myocardial blood flow, total oxidative metabolism, and left ventricular wall motion. Circ J 69:1459-1465

28. Nuutila P (1997) Applications of PET in diabetes research. Horm Metab Res 29:337-339

29. Chance B, Eleff S, Leigh JS Jr, Sokolow D, Sapega A (1981) Mitochondrial regulation of phosphocreatine/inorganic phos- phate ratios in exercising human muscle: a gated ${ }^{31} \mathrm{P}$ NMR study. Proc Natl Acad Sci USA 78:6714-6718

30. Binzoni T, Ferretti G, Schenker K, Cerretelli P (1992) Phosphocreatine hydrolysis by ${ }^{31} \mathrm{P}-\mathrm{NMR}$ at the onset of constant-load exercise in humans. J Appl Physiol 73:1644-1649

31. Vorgerd M, Schols L, Hardt C, Ristow M, Epplen JT, Zange J (2000) Mitochondrial impairment of human muscle in Friedreich ataxia in vivo. Neuromuscul Disord 10:430-435

32. Lodi R, Hart PE, Rajagopalan B et al (2001) Antioxidant treatment improves in vivo cardiac and skeletal muscle bioenergetics in patients with Friedreich's ataxia. Ann Neurol 49:590-596

33. Brown TR, Ugurbil K, Shulman RG (1977) ${ }^{31} \mathrm{P}$ nuclear magnetic resonance measurements of ATPase kinetics in aerobic Escherichia coli cells. Proc Natl Acad Sci USA 74:5551-5553

34. Jucker BM, Dufour S, Ren J et al (2000) Assessment of mitochondrial energy coupling in vivo by ${ }^{13} \mathrm{C} /{ }^{31} \mathrm{P}$ NMR. Proc Natl Acad Sci USA 97:6880-6884

35. Befroy DE, Petersen KF, Dufour S et al (2007) Impaired mitochondrial substrate oxidation in muscle of insulin-resistant offspring of type 2 diabetic patients. Diabetes 56:1376-1381

36. Schmid AI, Chmelik M, Szendroedi J et al (2008) Quantitative ATP synthesis in human liver measured by localized ${ }^{31} \mathrm{P}$ spectroscopy using the magnetization transfer experiment. NMR Biomed 21:437-444

37. Krssak M, Brehm A, Bernroider E et al (2004) Alterations in postprandial hepatic glycogen metabolism in type 2 diabetes. Diabetes 53:3048-3056

38. Bays H, Mandarino L, DeFronzo RA (2004) Role of the adipocyte, free fatty acids, and ectopic fat in pathogenesis of type 2 diabetes mellitus: peroxisomal proliferator-activated receptor agonists provide a rational therapeutic approach. J Clin Endocrinol Metab 89:463-478

39. Lazar MA (2006) The humoral side of insulin resistance. Nat Med 12:43-44

40. Petersen KF, Befroy D, Dufour S et al (2003) Mitochondrial dysfunction in the elderly: possible role in insulin resistance. Science 300:1140-1142

41. Petersen KF, Dufour S, Befroy D, Garcia R, Shulman GI (2004) Impaired mitochondrial activity in the insulin-resistant offspring of patients with type 2 diabetes. N Engl J Med 350:664-671

42. Brehm A, Krssak M, Schmid AI, Nowotny P, Waldhausl W, Roden M (2006) Increased lipid availability impairs insulinstimulated ATP synthesis in human skeletal muscle. Diabetes $55: 136-140$

43. Szendroedi J, Schmid AI, Chmelik M et al (2007) Muscle mitochondrial ATP synthesis and glucose transport/phosphorylation in type 2 diabetes. PLoS Med 4:e154

44. Rooyackers OE, Adey DB, Ades PA, Nair KS (1996) Effect of age on in vivo rates of mitochondrial protein synthesis in human skeletal muscle. Proc Natl Acad Sci USA 93:15364-15369

45. Guillet C, Prod'homme M, Balage M et al (2004) Impaired anabolic response of muscle protein synthesis is associated with S6K1 dysregulation in elderly humans. Faseb J 18:15861587

46. Volpi E, Sheffield-Moore M, Rasmussen BB, Wolfe RR (2001) Basal muscle amino acid kinetics and protein synthesis in healthy young and older men. JAMA 286:1206-1212

47. Melov S, Tarnopolsky MA, Beckman K, Felkey K, Hubbard A (2007) Resistance exercise reverses aging in human skeletal muscle. PLoS ONE 2:e465

48. Yarasheski KE, Zachwieja JJ, Campbell JA, Bier DM (1995) Effect of growth hormone and resistance exercise on muscle growth and strength in older men. Am J Physiol 268:E268-E276

49. Nair KS (2005) Aging muscle. Am J Clin Nutr 81:953-963

50. Rasmussen UF, Krustrup P, Kjaer M, Rasmussen HN (2003) Human skeletal muscle mitochondrial metabolism in youth and 
senescence: no signs of functional changes in ATP formation and mitochondrial oxidative capacity. Pflugers Arch 446:270-278

51. Bandy B, Davison AJ (1990) Mitochondrial mutations may increase oxidative stress: implications for carcinogenesis and aging? Free Radic Biol Med 8:523-539

52. Kimball SR, Vary TC, Jefferson LS (1994) Regulation of protein synthesis by insulin. Annu Rev Physiol 56:321-348

53. Petersen KF, Dufour S, Shulman GI (2005) Decreased insulinstimulated ATP synthesis and phosphate transport in muscle of insulin-resistant offspring of type 2 diabetic parents. PLoS Med 2:e233

54. Krebs M, Krssak M, Bernroider E et al (2002) Mechanism of amino acid-induced skeletal muscle insulin resistance in humans. Diabetes 51:599-605

55. Krebs M, Krssak M, Nowotny P et al (2001) Free fatty acids inhibit the glucose-stimulated increase of intramuscular glucose6-phosphate concentration in humans. J Clin Endocrinol Metab 86:2153-2160

56. Stump CS, Short KR, Bigelow ML, Schimke JM, Nair KS (2003) Effect of insulin on human skeletal muscle mitochondrial ATP production, protein synthesis, and mRNA transcripts. Proc Natl Acad Sci USA 100:7996-8001

57. Rorsman P (1997) The pancreatic beta-cell as a fuel sensor: an electrophysiologist's viewpoint. Diabetologia 40:487-495

58. Stark R, Roden M (2007) ESCI Award 2006. Mitochondrial function and endocrine diseases. Eur J Clin Invest 37:236-248

59. Kibbey RG, Pongratz RL, Romanelli AJ, Wollheim CB, Cline GW, Shulman GI (2007) Mitochondrial GTP regulates glucosestimulated insulin secretion. Cell Metab 5:253-264

60. Szendroedi J, Schmid AI, Kacerovsky M et al (2008) Impaired mitochondrial function and insulin resistance of skeletal muscle in mitochondrial diabetes. Diabetologie und Stoffwechsel 3(Suppl 1):S102 (Abstract)

61. Lowell BB, Shulman GI (2005) Mitochondrial dysfunction and type 2 diabetes. Science 307:384-387

62. Szendroedi JM, Zwettler E, Schmid AI et al (2007) Muscle mitochondrial dysfunction and reduced beta cell function in patients with previous acromegaly. Diabetologia 50(Suppl 1): S314 (Abstract)

63. Simoneau JA, Kelley DE (1997) Altered glycolytic and oxidative capacities of skeletal muscle contribute to insulin resistance in NIDDM. J Appl Physiol 83:166-171

64. Ritov VB, Menshikova EV, He J, Ferrell RE, Goodpaster BH, Kelley DE (2005) Deficiency of subsarcolemmal mitochondria in obesity and type 2 diabetes. Diabetes 54:8-14

65. Boushel R, Gnaiger E, Schjerling P, Skovbro M, Kraunsoe R, Dela F (2007) Patients with type 2 diabetes have normal mitochondrial function in skeletal muscle. Diabetologia 50:790-796

66. Pette D, Spamer C (1986) Metabolic properties of muscle fibers. Fed Proc 45:2910-2914

67. Mogensen M, Sahlin K, Fernstrom M et al (2007) Mitochondrial respiration is decreased in skeletal muscle of patients with type 2 diabetes. Diabetes 56:1592-1599

68. Marin P, Andersson B, Krotkiewski M, Bjorntorp P (1994) Muscle fiber composition and capillary density in women and men with NIDDM. Diabetes Care 17:382-386

69. Hickey MS, Carey JO, Azevedo JL et al (1995) Skeletal muscle fiber composition is related to adiposity and in vitro glucose transport rate in humans. Am J Physiol 268:E453-E457

70. Zierath JR, He L, Guma A, Odegoard Wahlstrom E, Klip A, Wallberg-Henriksson H (1996) Insulin action on glucose transport and plasma membrane GLUT4 content in skeletal muscle from patients with NIDDM. Diabetologia 39:1180-1189

71. Sreekumar R, Halvatsiotis P, Schimke JC, Nair KS (2002) Gene expression profile in skeletal muscle of type 2 diabetes and the effect of insulin treatment. Diabetes 51:1913-1920
72. Schrauwen-Hinderling VB, Kooi ME, Hesselink MK et al (2007) Impaired in vivo mitochondrial function but similar intramyocellular lipid content in patients with type 2 diabetes mellitus and BMI-matched control subjects. Diabetologia 50: 113-120

73. Pessayre D, Fromenty B, Mansouri A (2004) Mitochondrial injury in steatohepatitis. Eur J Gastroenterol Hepatol 16:10951105

74. Sanyal AJ, Campbell-Sargent C, Mirshahi F et al (2001) Nonalcoholic steatohepatitis: association of insulin resistance and mitochondrial abnormalities. Gastroenterology 120:11831192

75. Beck-Nielsen H, Vaag A, Poulsen P, Gaster M (2003) Metabolic and genetic influence on glucose metabolism in type 2 diabetic subjects - experiences from relatives and twin studies. Best Pract Res Clin Endocrinol Metab 17:445-467

76. Perseghin G, Ghosh S, Gerow K, Shulman GI (1997) Metabolic defects in lean nondiabetic offspring of NIDDM parents: a crosssectional study. Diabetes 46:1001-1009

77. Ukropcova B, Sereda O, de Jonge L et al (2007) Family history of diabetes links impaired substrate switching and reduced mitochondrial content in skeletal muscle. Diabetes 56:720-727

78. Morino K, Petersen KF, Dufour S et al (2005) Reduced mitochondrial density and increased IRS-1 serine phosphorylation in muscle of insulin-resistant offspring of type 2 diabetic parents. J Clin Invest 115:3587-3593

79. Meigs JB, Larson MG, Fox CS, Keaney JF Jr, Vasan RS, Benjamin EJ (2007) Association of oxidative stress, insulin resistance, and diabetes risk phenotypes: the Framingham Offspring Study. Diabetes Care 30:2529-2535

80. Ortenblad N, Mogensen M, Petersen I et al (2005) Reduced insulin-mediated citrate synthase activity in cultured skeletal muscle cells from patients with type 2 diabetes: evidence for an intrinsic oxidative enzyme defect. Biochim Biophys Acta 1741:206-214

81. Toledo FG, Watkins S, Kelley DE (2006) Changes induced by physical activity and weight loss in the morphology of intermyofibrillar mitochondria in obese men and women. J Clin Endocrinol Metab 91:3224-3227

82. Pette D, Hofer HW (1979) The constant proportion enzyme group concept in the selection of reference enzymes in metabolism. Ciba Found Symp 73:231-244

83. Krotkiewski M, Bylund-Fallenius AC, Holm J, Bjorntorp P, Grimby G, Mandroukas K (1983) Relationship between muscle morphology and metabolism in obese women: the effects of long-term physical training. Eur J Clin Invest 13:5-12

84. Vondra K, Rath R, Bass A, Slabochova Z, Teisinger J, Vitek V (1977) Enzyme activities in quadriceps femoris muscle of obese diabetic male patients. Diabetologia 13:527-529

85. Kelley DE, Mandarino LJ (2000) Fuel selection in human skeletal muscle in insulin resistance: a reexamination. Diabetes 49:677-683

86. Ukropcova B, McNeil M, Sereda O et al (2005) Dynamic changes in fat oxidation in human primary myocytes mirror metabolic characteristics of the donor. J Clin Invest 115:1934-1941

87. Bogardus C, Lillioja S, Mott D, Zawadzki J, Young A, Abbott W (1985) Evidence for reduced thermic effect of insulin and glucose infusions in Pima Indians. J Clin Invest 75:1264-1269

88. Pittet P, Chappuis P, Acheson K, De Techtermann F, Jequier E (1976) Thermic effect of glucose in obese subjects studied by direct and indirect calorimetry. Br J Nutr 35:281-292

89. Pelsers MM, Tsintzas K, Boon H et al (2007) Skeletal muscle fatty acid transporter protein expression in type 2 diabetes patients compared with overweight, sedentary men and agematched, endurance-trained cyclists. Acta Physiol (Oxf) 190: 209-219 
90. Hertzel AV, Smith LA, Berg AH et al (2006) Lipid metabolism and adipokine levels in fatty acid-binding protein null and transgenic mice. Am J Physiol Endocrinol Metab 290:E814-E823

91. Kahn BB, Alquier T, Carling D, Hardie DG (2005) AMPactivated protein kinase: ancient energy gauge provides clues to modern understanding of metabolism. Cell Metab 1:15-25

92. Clark H, Carling D, Saggerson D (2004) Covalent activation of heart AMP-activated protein kinase in response to physiological concentrations of long-chain fatty acids. Eur J Biochem 271:2215-2224

93. Moore GB, Himms-Hagen J, Harper ME, Clapham JC (2001) Overexpression of UCP-3 in skeletal muscle of mice results in increased expression of mitochondrial thioesterase mRNA. Biochem Biophys Res Commun 283:785-790

94. Stavinoha MA, RaySpellicy JW, Essop MF et al (2004) Evidence for mitochondrial thioesterase 1 as a peroxisome proliferatoractivated receptor-alpha-regulated gene in cardiac and skeletal muscle. Am J Physiol Endocrinol Metab 287:E888-E895

95. Kim JY, Koves TR, Yu GS et al (2002) Evidence of a malonylCoA-insensitive carnitine palmitoyltransferase I activity in red skeletal muscle. Am J Physiol Endocrinol Metab 282:E1014-E1022

96. Schrauwen P, Hesselink MK (2004) Oxidative capacity, lipotoxicity, and mitochondrial damage in type 2 diabetes. Diabetes 53:1412-1417
97. Hamilton JA (2003) Fast flip-flop of cholesterol and fatty acids in membranes: implications for membrane transport proteins. Curr Opin Lipidol 14:263-271

98. Skulachev VP (1998) Uncoupling: new approaches to an old problem of bioenergetics. Biochim Biophys Acta 1363:100-124

99. Echtay KS, Esteves TC, Pakay JL et al (2003) A signalling role for 4-hydroxy-2-nonenal in regulation of mitochondrial uncoupling. Embo J 22:4103-4110

100. Koves TR, Ussher JR, Noland RC et al (2008) Mitochondrial overload and incomplete fatty acid oxidation contribute to skeletal muscle insulin resistance. Cell Metab 7:45-56

101. Lattuada G, Costantino F, Caumo A et al (2005) Reduced wholebody lipid oxidation is associated with insulin resistance, but not with intramyocellular lipid content in offspring of type 2 diabetic patients. Diabetologia 48:741-747

102. Larson-Meyer DE, Newcomer BR, Hunter GR, McLean JE, Hetherington HP, Weinsier RL (2000) Effect of weight reduction, obesity predisposition, and aerobic fitness on skeletal muscle mitochondrial function. Am J Physiol Endocrinol Metab 278: E153-E161

103. Scheuermann-Freestone M, Madsen PL, Manners D et al (2003) Abnormal cardiac and skeletal muscle energy metabolism in patients with type 2 diabetes. Circulation 107:3040-3046 